\title{
Emergence Impacts of Mobile Commerce: An Exploratory Study
}

\author{
Chiang-nan Chao ${ }^{1}$ \\ ${ }^{1}$ The Peter J. Tobin College of Business, St. John's University, Queens, USA \\ Correspondence: Chiang-nan Chao, The Peter J. Tobin College of Business, St. John's University, Queens, NY \\ 11439, USA.
}

Received: April 24, 2017

Accepted: May 12, 2017

Online Published: June 1, 2017

doi:10.5430/jms.v8n2p63

URL: https://doi.org/10.5430/jms.v8n2p63

\begin{abstract}
Mobile commerce, known as mcommerce, has emerged as an important sector in retail businesses, as US smartphones have penetrated near $80 \%$ of the population in 2017 . The average adult daily usage of smart phone outpaced personal computers for the first time, and the users do more commerce on their smartphones than on their personal computers. As predicted by eMarketer US mcommerce will be a half of the total ecommerce by 2020 . As a result, marketers have spent advertisement on smartphones. The marketers realize that they can better target smartphone users through programmatic advertising, particularly when they find the phone users are interested in particular products they browse. This research, through an empirical survey, focuses on the effectiveness of mobile marketing. The research results confirm this marketing trend, and provide some useful insights for marketers in their future marketing endeavors.
\end{abstract}

Keywords: mobile commerce, mcommerce, electronic commerce, ecommerce

\section{Introduction}

US retail mcommerce sales increased $43.2 \%$ in 2016 to $\$ 115.92$ billion. That translates to $29.1 \%$ of retail ecommerce sales and $2.4 \%$ of total retail sales for the year. The bulk of US retail mcommerce growth is occurring on smartphones, as US smart phone has penetrated nearly $80 \%$ of the population in 2016 , and the average adult daily usage of smart phone had outpaced the uses of personal computers for the first time a year earlier [eMarketer, (2016).

According to the eMarketer's prediction, advertisers will spent $\$ 50.84$ billion on U.S. digital advertising by the end of 2017, while Ad spending on TV will account for $\$ 72.6$ billion. The advertisement spending on digital media, including both mobile and computers will reach about $\$ 74$ billion, more than that spent on TV [eMarketer (2017).. Adults spent more hours on their smart phones than on their computers, and the data traffic for mobile is predicted to have 54\% of annual compound growth rate from 2015 through 2020 (Cisco, 2016).

Fourth-generation $(4 \mathrm{G})$ traffic exceeded third-generation $(3 \mathrm{G})$ traffic for the first time in 2015. Although $4 \mathrm{G}$ connections represented only 14 percent of mobile connections in 2015, they already account for 47 percent of mobile data traffic, while $3 \mathrm{G}$ connections represented 34 percent of mobile connections and 43 percent of the traffic. In 2015 , a $4 \mathrm{G}$ connection generated six times more traffic on average than a non-4G connection. Mobile offload exceeded cellular traffic for the first time in 2015. Fifty-one percent of total mobile data traffic was offloaded onto the fixed network through Wi-Fi or femtocell in 2015. In total, 3.9 exabytes of mobile data traffic were offloaded onto the fixed network each month.

This empirical study intends to compare the effectiveness of mobile advertising, aiming to reveal some insights that can help advertisers with their strategic thinking.

\section{Review of Literature}

Due to the wide availability of $3 \mathrm{G}$ and $4 \mathrm{G}$ mobile communication systems, more people around the globe are able to browse the web for a variety of products via their smartphones. According to eMarketer, mobile advertising spending shares have enjoyed double digit growth in the recent years. At the same time, traditional advertising spending has remained nearly flat. Figure 1 presents the projected traditional media advertising spending and digital advertising spending in the US market. 


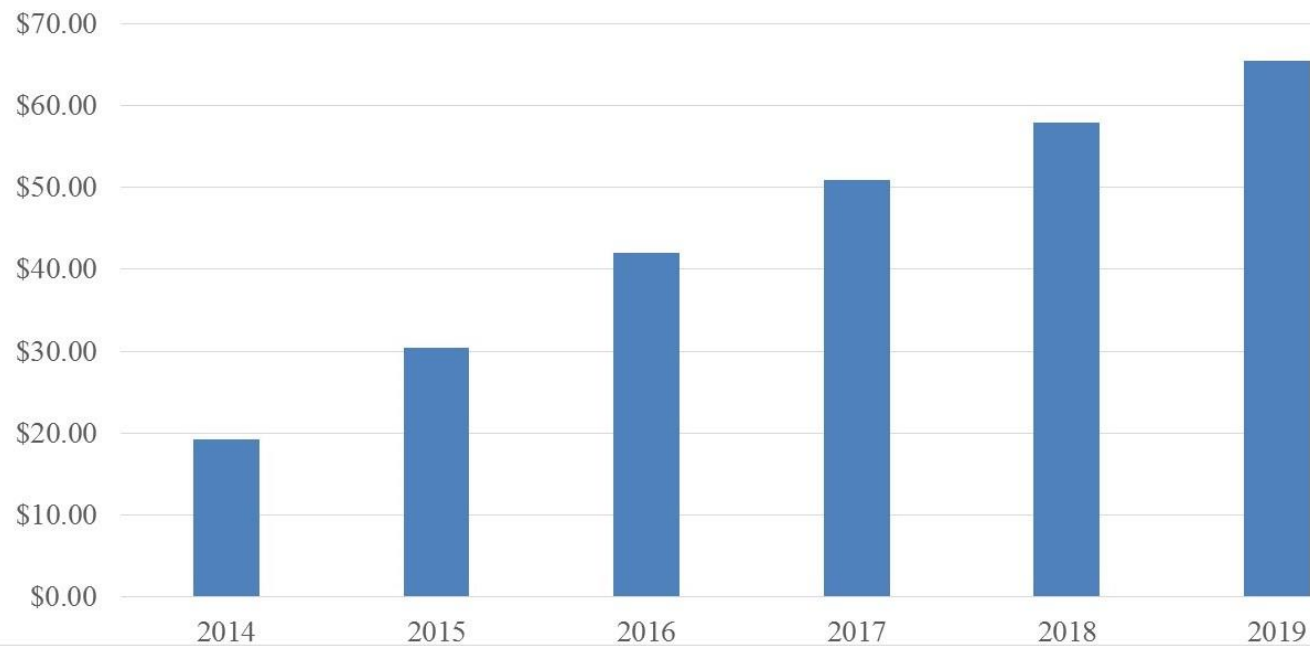

Figure 1. US mobile advertisement spending, 2014-2019, in US\$ bil

Source:

https://www.emarketer.com/Article/Mobile-Ad-Spend-Top-100-Billion-Worldwide-2016-51-of-Digital-Market/1012 299

During the past years, adults have spent more time on their mobile phones than on the personal computers, and the trend will continue. Figure 2 illustrates the changes.

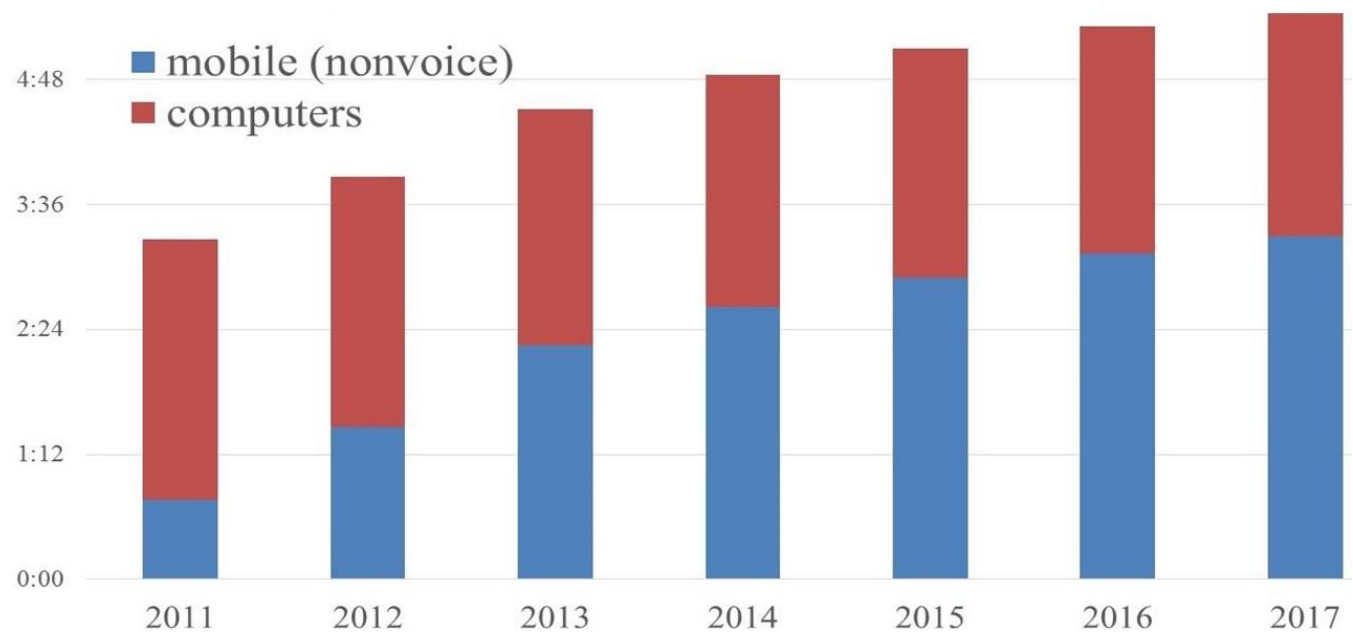

Figure 2. Time spent per adult user per day with digital media, USA

Source: http://www.smartinsights.com/mobile-marketing/mobile-marketing-analytics/mobile-marketing-statistics/

As with every industry, the movers and shakers will always follow the money. For the first time in TV history, the money isn't being funneled toward actual TVs. Instead, digital platforms continue to eat up more and more business, and U.S. digital ad sales surpassed traditional TV for the first time at the end of 2016. This marks a massive shift in the way business is conducted. It's a new paradigm for the TV industry that threatens the viability of the old model similar to how the rise in mobile gaming has stunted the growth of portable gaming systems (Katz, 2016).

Marketers who look only at the bottom-line effects of mobile shopper activities on retailing are missing important clues about the future. "Mobile still is not a significant channel in driving actual purchases," observe comScore, Inc. CEO, Gian M. Fulgoni, and VP of Marketing and Insights, Andrew Lipsman. Yet, "data from Deloitte forecast that in 2016, mobile will have influenced $\$ 689$ billion in U.S. in-store sales, up from just $\$ 158$ billion in $2012-\mathrm{a}$ compound annual growth rate of 45 percent. These mobile-influenced sales figures account for in-store product purchases for which a mobile device aided in the shopping experience.” (Fulgoni, et al 2016). 
Another window onto the future of a mobile-driven retail sector: channel growth - the year-over-year rate of spending growth within brick-and mortar, desktop, and mobile retail sectors. Mobile's 49 percent year-over-year channel growth rate in the 2015 holiday shopping season "meant that it had an overall retail growth contribution of 1.2 points out of the total estimated retail growth of 3.9 percent. In other words," the authors write, "mobile represented about 30 percent of the growth contribution, despite only directly contributing 2.4 percent of discretionary spending. That growth contribution outpaced that of desktop e-commerce and was not so far behind the 2.0 percent contribution of the brick and-mortar channel." Marketers should take cues from big retailers like Amazon, eBay, Target and Kohl's that have created successful mobile apps that address a broad range of customer needs, and from research demonstrating that mobile advertising that can be more effective than online (Fulgoni \& Lipsman, 2016).

The study by Liang, et al discusses the rapid adoption of smartphones, developing mobile apps has become an attractive arena for entrepreneurs. The effect of textual consumer reviews on the sales of mobile apps is examined. Employing a real-world data set of seventy-nine paid and seventy free apps from an iOS app store, the authors found that although consumers' opinions on product quality occupies a larger portion of consumer reviews, their comments on service quality have a stronger unit effect on sales rankings. The empirical analysis illustrates the value of the authors' proposed multifacet sentiment analysis (MFSA) approach for better understanding of the effect of textual consumer reviews on mobile app success. (Liang, et al 2015)

Pousttchi, et al study m-commerce in the smartphone age and concludes that $\mathrm{m}$-commerce is revolutionizing established value networks and transforming the wider economy. They examine more than a decade of research and reveal significant changes in $\mathrm{m}$-commerce topics as time goes on, and provides initial insights into the future. They believe that the m-commerce field has still to establish a strong theoretical foundation (Pousttchi, et al 2015).

Wang, et al (2015) examine mobile commerce technologies cater to multiple types of users who use them for various purposes in a dynamic fashion over time. They address the complex sociotechnical setting by investigating the "biography" of mobile text messaging, an instance of mobile commerce technologies, in China. They apply an actor-network perspective to understand the development and diffusion of text messaging over time and the changing actor configurations. Their analysis was based on 1,403 news items pertaining to the Chinese telecommunications market, which were screened from over 40,000 news items produced over sixteen years. The deduced pattern indicates that the diffusion of text messaging, and possibly other mobile commerce technologies, includes four actor network configurations. M-commerce platforms begin to operate within a small network of actors, and via a dynamic process of events and interactions, they end up with a complex network of actors, which can include content and service providers, customers, regulators, and businesses that drive mobile commerce technology diffusion and breadth of uses across markets. The suggested pattern provides a "biography of artifacts" regarding mobile technologies at the national level. (Wang, et al 2015)

Huang and Korfiatis (2016) review mobile app marketplaces that help consumers evaluate whether a mobile app fits their needs before upgrading or purchasing it. This study explores how online reviews influence trial attitude formation, a process that naturally bears on cognitive structure as much as on users' emotional responses to online experience. They experimentally manipulate the valence (positive vs. negative) and consistency (one-sided vs. two-sided) of online reviews exposed to participants in a laboratory-controlled app trial scenario considering two different aspects of use (hedonic and functional). They find that review valence and consistency alter the emotional process during trial attitude formation but do not affect the cognitive process. In particular, negative reviews compared to positive reviews and two-sided reviews compared to one-sided reviews are more influential in trial attitude formation. Interestingly, two-sided reviews weaken the emotional process during the use of functional apps, but strengthen it during the use of hedonic apps. The study contributes to the literature by identifying the moderating role of online reviews on product trial experience, which in turn influences the formation of product attitudes. The findings help app developers and marketers understand how to elicit positive evaluations during app trials by highlighting the importance of online reviews (Huang \& Korfiatis, 2015).

Chao, et al (2012) investigated the emergence of online advertising as a prominent promotion vehicle that has prompted businesses around the globe to strategically shift their focus to online media. The research results reveal traditional media advertising are still effective, and suggest that marketers need to balance online and traditional media advertising in order to better target their customers. This study, however, did not include a mobile communication sector.

Flosi et al (2013) tried to identify and to better understand the incidence of sub-optimal digital campaign delivery as it pertains to viewability, audience delivery, geographic targeting, and brand safety. The study highlighted and 
evaluated the implications for the digital advertising ecosystem of several significant empirical generalizations that have emerged.

Wang, et al (2013) examined the impacts of exposure duration and banner ad complexity on advertising persuasion in a web advertising environment. Their findings show that, when a banner ad is difficult to process in the priming phase, increasing the duration of exposure to the ad in the priming phase causes a linear increase in respondent attitudes towards the target ad and brand in the testing phase.

Edelman (2014) examines ineffectiveness problems that result, in part, from malfeasance by outside perpetrators who overstate their efforts to increase their measured performance. In parallel, similar vulnerabilities result from mistaken analysis of cause and effect - errors that have become more fundamental as advertisers target their advertisements with greater precision. The author attempts to identify the circumstances that make advertisers most vulnerable, notes adjusted contract structures that offer some protections, and explores the origins of the problems in participants' incentives and in legal rules.

Cook (2014) investigates online advertising on smartphone and tablets. He challenges researchers to improve survey taking on mobile devices. He believes that over the next five years, the use of touch-screen mobile devices will grow dramatically, and respondents can be expected to use them at a higher rate, as the screens expand (somewhat) and the devices gain more multi-purpose media use.

The review of literature tenders a wide range of aspects for both digital (computers) and mobile advertising. While this study intends to focus only on the fundamental issues, it is a comparison of the effectiveness of digital advertising on computers and on mobile phone. The objective of the study is to provide some insights to marketers that would improve the effectiveness of their advertising.

\section{Methodology}

Present study captures consumer perceptions of traditional and digital advertisement effectiveness, focusing on a segment that is often targeted by both traditional and digital advertisers. A survey questionnaire was designed to investigate the features that were most important for the advertisers.

\subsection{Variable Selection}

The variables that were selected are based on our literature review. Twelve research variables were identified from the review of literature and presented below. The respondents were asked to identify how frequently they were aware of the advertising messages, presented either in the digital form or in the form of the traditional media. The respondents were asked to evaluate the frequency they would notice each of these variable messages advertised in digital advertising and in traditional media advertising. Five point Likert scale is applied, with $5=$ always, $4=$ mostly, $3=$ frequently, $2=$ occasionally, $1=$ never.

The following variables were evaluated:

1. Product quality and features offering

2. $\quad$ Offering free samples

3. Offering free trials

4. Offering attractive prices

5. Offering discounts and promotion

6. Offering coupons

7. Offering rebates

8. Offering incentives to buyers in online store or retail stores

9. Offering free delivery or delivery incentives

10. Offering prizes

11. Offering sweepstakes

12. Offering sport or cultural sponsorship

\subsection{Sampling, Hypotheses, and Tests of Hypotheses}

The targeted sample respondents were college students in a large university in the northeast of the U.S. One-page survey questionnaires were distributed online over past semesters to target respondents, specifically with the aim of 
obtaining the opinions of the respondents who are often exposed to both traditional and digital advertising. The null hypotheses for this study stated:

$H_{l} \quad$ There is no significant difference in product quality and/or features offering between mobile media and computerllaptop advertising.

$\mathrm{H}_{2} \quad$ There is no significant difference in offering free samples between mobile media and computer/laptop advertising.

$\mathrm{H}_{3} \quad$ There is no significant difference in offering free trials between mobile media and computer/laptop advertising.

$H_{4} \quad$ There is no significant difference in offering attractive prices between mobile media and computer/laptop advertising.

$\mathrm{H}_{5} \quad$ There is no significant difference in offering discounts and promotion between mobile media and computer/laptop advertising.

$H_{6} \quad$ There is no significant difference in offering coupons between mobile media and computer/laptop advertising.

$H_{7} \quad$ There is no significant difference in offering rebates between mobile media and computer/laptop advertising.

$H_{8} \quad$ There is no significant difference in offering incentives to buyers in mobile media store or retail stores between mobile media and computer/laptop advertising.

$H_{9} \quad$ There is no significant difference in offering free delivery or delivery incentives between mobile media and computer/laptop advertising.

$H_{10} \quad$ There is no significant difference in offering prizes between mobile media and computer/laptop advertising.

$H_{11} \quad$ There is no significant difference in offering sweepstakes between mobile media and computer/laptop advertising.

$H_{12} \quad$ There is no significant difference in offering sport or cultural sponsorship between mobile media and computer/laptop advertising.

The alternative hypotheses state: there is significant relationship between the respondents' views of mobile media advertising and computer/laptop advertising over these selected variables.

When two samples are involved and the values for each sample are collected from the same individuals (that is, each individual gives two values, one for each of the two categories), or the samples come from matched pairs of individuals, the Marginal Homogeneity Test can be used. If the significance level is less than the desired level, then the dependent sample means will be different, and if the significance level is greater than the desired level, then the mean of the dependent samples will be the same. It tests whether combinations of values between two paired ordinal variables are equally likely. The marginal homogeneity test is typically used in repeated measures situations. Since the data collected in this study is of ordinal scaling, as the respondents were asked to provide their opinions on the paired variables: digital advertising and traditional media advertising, the use of marginal homogeneity test is appropriate. The null hypotheses should be rejected if the significance level is less than or equal to 5\% in any one criterion (Hamburg, 1977; Conover, 1980; Davis and Cosenza, 1985; IBM SPSS Exact Tests, SPSS Inc. 2010).

\section{Results}

Over thousand two hundred questionnaires were distributed in a large metropolitan area in the northeast of the U.S., of which five hundred eighty five were returned, of which five hundred seventy three were usable. This represents roughly 47.75 percent response rate. The following table presents the background information of these respondents, including gender and income. 
Table 1. Background Information of the respondents

\begin{tabular}{cr}
\hline 1. age & $\%$ \\
$<18$ & 1.9 \\
$19-35$ & 94.6 \\
$36-50$ & 3.1 \\
$>50$ & 0.4 \\
2. gender & $\%$ \\
male & 55.2 \\
female & 44.8 \\
3. family income & $\%$ \\
$<35 \mathrm{k}$ & 16.9 \\
35-50k & 21.1 \\
50-75k & 21.1 \\
$>75 \mathrm{k}$ & 41.0 \\
4. education & $\%$ \\
College & 87.3 \\
Graduate & 12.7 \\
5. marital status & $\%$ \\
Married & 10.0 \\
Single & 90.0 \\
6. have smartphone & $\%$ \\
Yes & 97.7 \\
No & 2.3 \\
\hline
\end{tabular}

Overall, the means of computer internet advertising are higher than those of smartphone advertising. Table 2 shows the Marginal Homogeneity Test results. It indicates that only one of paired variables test result shows significance levels less than 5\% (highlighted in bold). Therefore, one hypothesis where there is significant differences between the respondents' views of smartphone advertising versus computer internet advertising messages is rejected. The other 11 paired variables test results show significance levels more than 5\%. Therefore, these hypotheses are accepted: for these promotional elements there are no significant differences in the respondents' awareness based on smartphone advertising messages and the computer internet advertising messages.

Table 2. The marginal homogeneit tests

\begin{tabular}{lcc}
\hline Variables & Mean MH & Sig. (2-tailed) \\
\hline Product quality and features offering & 193.5 & 0.206 \\
Offering free samples & 172.5 & 0.299 \\
Offering free trials & 201.5 & 0.119 \\
Offering attractive prices & 181.0 & 0.391 \\
Offering discounts and promotion & $\mathbf{2 3 5 . 0}$ & $\mathbf{0 . 0 2 0}$ \\
Offering coupons & 201.0 & 0.553 \\
Offering rebates & 141.5 & 0.386 \\
Offering incentives to buyers in online store or retail stores & 179.0 & 0.299
\end{tabular}




$\begin{array}{lll}\text { Offering free delivery or delivery incentives } & 186.5 & 0.574 \\ \text { Offering prizes } & 146.5 & 0.812 \\ \text { Offering sweepstakes } & 120.0 & 0.710 \\ \text { Offering sport or cultural sponsorship } & 142.0 & 0.098\end{array}$

\section{Managerial Implications and Recommendations}

The Marginal Homogeneity Test results reject only one of the twelve null hypotheses; therefore, the study cannot conclude that there are statistically significant differences from the consumers' viewpoints between smartphone and computer internet advertising. The findings suggest that computer internet will continue to hold its position as a result of the rise of smartphone. The two may work more effectively together to yield better advertising.

The rejection of Offering discounts and promotion indicates the smartphone users tend to explore the offers of various products and/or services on their smartphone, as it is much easier for the users to access these offers. This rejection result offers a glimpse that more promotion can be better targeted the potential buyer groups via smartphones, rather than on the computer internet.

This study accepts eleven hypotheses: Product quality and features offering, Offering free samples, Offering free trials, Offering attractive prices, Offering discounts and promotion, Offering coupons, Offering rebates, Offering incentives to buyers in online store or retail stores, Offering free delivery or delivery incentives, Offering prizes, Offering sweepstakes, Offering sport or cultural sponsorship as there are no statistically significant differences in effectiveness of the listed marketing activities between smartphone and computer internet advertising. This may suggest, from the consumers' viewpoints, it is less important for advertisers focusing on these issues when they are allocating funds to different advertising media.

The findings of this study may also suggest that computer internet advertising may not be a more effective way to send the messages to the target customers as compared to the smartphone advertising messages. Credibility of this suggestion should be tested further, as this study has a preliminary nature. Smartphone advertising has emerged as a great challenge to computer internet advertising, not only because of its many advantages, but also because it gives advertisers an additional vehicle to reach their potential customers and often obtain instant feedback.

While researchers are inquiring the truth, practitioners are experimenting with new ways to reach their target customers; therefore the crowded advertising market is getting more crowded. The results of this research also suggest that smartphone advertising has a strong presence, and it will work hand-in-hand with computer internet advertising. A strategic balancing between the computer internet and smartphone advertising will make advertising industry more effective.

\section{Limitations and Future Research}

The academic research that focuses on comparisons between computer internet and smartphone advertising is limited, and it may take some years before significant research publications are available. As a preliminary and exploratory research, this study has provided if only limited glimpses of some fundamental aspects of smartphone advertising.

Further in-depth research should delve more into the factors and elements that predict the effectiveness of computer internet versus smartphone advertising. Would consumers eventually prefer more smartphone advertising in the future? Does the younger generation differ from the older generation since younger people work more smartphone? As some of the respondents commented, they find using the smartphone enable them to handily obtain products and/or service related information. These issues should also be addressed in future research.

\section{References}

Chao, C. N., Corus, C., \& Li, T. (2012). Balancing Traditional Media and Online Advertising Strategy, International Journal of Business, Marketing, and Decision Sciences, 5(2), 12-24.

Cisco, (2017). Virtual Network Index Report. Retrieve from http://www.cisco.com/c/en/us/solutions/collateral/service-provider/visual-networking-index-vni/mobile-white-p aper-c11-520862.html

Conover, W. J. (1980). Practical Nonparametric Statistics (2nd ed.). New York: John Wiley \& Sons, pp. 213-337 \& 344-384. 
Cook, W. A. (2014). Research Quality: Is Mobile a Reliable Platform for Survey Taking?. Journal of Advertising Research, 54(2), 141-148. http://dx.doi.org/10.2501/jar-54-2-141-148

Davis, D., \& Cosenza R. M. (1985). Business Research for Decision Making. Boston: Kent Publishing.

Edelman, B. (2014). Lessons: Pitfalls and Fraud in Online Advertising Metrics. Journal of Advertising Research, 54(2), 127-132. http://dx.doi.org/10.2501/jar-54-2-127-132

eMarketer, Retrieved from https://www.emarketer.com/Article/Holiday-Retail-Ecommerce-Sales-Will-Grow-17-this-Year/1014529\#sthash .81 ZussJQ.dpuf

eMarketer.

(2017).

Retrieved

from http://www.emarketer.com/Article/Mobile-Account-More-than-Half-of-Digital-Ad-Spending-2015/1012930

Flosi, S., Fulgoni, G., \& Vollman, A. (2013). If an Advertisement Runs Online and No One Sees It, Is It Still an Ad? Empirical Generalizations in Digital Advertising. Journal of Advertising Research, 53(2), 192-199. http://dx.doi.org/10.2501/jar-53-2-192-199

Fulgoni, G. M., \& Lipsman, A. (2016, June). The Future of Retail Is Mobile, Journal of Advertising Research, 56(4), 346-351. http://dx.doi.org/10.2501/JAR-2016-041

Hamburg, M. (1977). Statistical Analysis for Decision Making. San Diego: Harcourt.

Huang, G. H., \& Korfiatis, N. (2015). Trying Before Buying: The Moderating Role of Online Reviews in Trial Attitude Formation toward Mobile Applications. International Journal of Electronic Commerce, 19(4), 77-111. http://dx.doi.org/10.1080/10864415.2015.1029359

IBM SPSS Exact Tests, SPSS Inc. 2010.

Katz, B. (2016). Digital Ad Spending Will Surpass TV Spending for the First Time in U.S. History, Forbes, Sep 14. Retrived from https://www.forbes.com/sites/brandonkatz/2016/09/14/digital-ad-spending-will-surpass-tv-spending-for-the-firs t-time-in-u-s-history/\#47b0cebd4207

Liang, T. P., Li, X., Yang, C. T., \& Wang, M. (2015). What in Consumer Reviews Affects the Sales of Mobile Apps: A Multifacet Sentiment Analysis Approach. International Journal of Electronic Commerce, 20(2), 236-260. http://dx.doi.org/10.1080/10864415.2016.1087823

Pousttchi, K., Tilson, D., Lyytinen, K., \& Yvonne Hufenbach, Y. (2015). Introduction to the Special Issue on Mobile Commerce: Mobile Commerce Research Yesterday, Today, Tomorrow-What Remains to Be Done? International Journal of Electronic Commerce, 19(4), 1-20.

Wang, K. Y., Shih, E., \& Peracchio, L (2013). How banner ads can be effective: Investigating the influences of exposure duration and banner ad complexity. International Journal of Advertising, 32(1), 121-141. http://dx.doi.org/10.2501/ija-32-1-121-141

Wang, Y., Yuan, Y., Turel, O., \& Tu, Z (2015). Understanding the Development and Diffusion of Mobile Commerce Technologies in China: A Biographical Study with an Actor-Network Theory Perspective. International Journal of Electronic Commerce, 19(4), 47-76. http://dx.doi.org/10.1080/10864415.2015.1029358 